\title{
História da leitura, hipertexto e utopia digital
}

Sérgio Luiz Prado Bellei(UFMG)

Recebido 21 jul. 2013/Aprovado 22 abr. 2014

\section{Resumo}

O entendimento utópico do hipertexto eletrônico como uma tecnologia capaz de revolucionar hábitos de leitura e dar mais poder ao leitor só pode prosperar na medida em que afirma a natureza da tecnologia em termos de uma estrutura meramente instrumental e marginaliza a sua percepção enquanto força estruturante, ou seja, capaz de produzir uma nova economia cultural de valores. O presente trabalho propõe uma crítica da visão instrumental e operacional das novas tecnologias, a ser desenvolvida a partir de trabalhos pioneiros já iniciados por teóricos como Martin L. Rosenberg e Roger Chartier.

Palavras-chave: hipertexto; utopia digital; crítica da tecnologia. 


\section{Introdução}

O aparecimento de uma nova tecnologia traz geralmente consigo uma ênfase instantânea no que se poderia chamar de "perspectiva operacional". Trata-se de entender, de imediato, como a nova tecnologia funciona através do seu uso sistemático no maior número possível de práticas. Via de regra, essa ênfase operacional vem acompanhada de um otimismo exagerado a respeito do potencial da nova tecnologia. David Noble ajuda a entender o exagero desse otimismo quando aponta para suas possíveis origens e função em termos de milenarismo religioso e profético, de um lado, e de lucro tecnocrático, de outro. A obsessão da cultura ocidental com a tecnologia não é novidade. Lembrando, contudo, que essa cultura é também judaico-cristã, Noble dá um passo adiante e sugere que, particularmente em seu desenvolvimento a partir de Francis Bacon e dos fundadores da ciência moderna, a proposta da ciência identifica-se com o milenarismo religioso. Trata-se, nos dois casos, de afirmar nada mais nada menos do que a possibilidade de transcendência da queda originária com o objetivo de recuperar o paraíso perdido, seja através da espera do milenarismo religioso por vir, seja através do exercício das artes mecânicas voltadas para a possibilidade de um futuro melhor. Ciência e religião tornam-se, para Noble, formas culturais de escatologia orientadas para uma Nova Jerusalém, objetivo último não apenas das práticas cristãs, mas também da tecno-ciência moderna: a conquista do espaço, a engenharia genética, a ciência nuclear e, mais recentemente, a inteligência artificial. São também, em todos os casos, áreas indissociáveis do lucro e do capital. Na passagem do milênio, evidentemente, é fácil constatar que a Nova Jerusalém não chegou. Tudo indica que, ao contrário, não chegará jamais, e que a procura da salvação pela tecnologia representa mais uma ameaça à humanidade do que um resgate. É que, como conclui Noble (1999),

em um nível cultural mais profundo, essas tecnologias não atenderam às necessidades humanas básicas porque, no fundo, nunca tiveram tal intenção. Seus esforços foram antes dirigidos para o objetivo mais elevado de transcender essas preocupações mortais. Nesse contexto ideológico, inspiradas mais pelos profetas do que pelo lucro, são pouco significativas as necessidades dos mortais e das regiões que habitam. E é justamente nesse contexto que a religião da tecnologia pode ser acertadamente entendida como uma ameaça. (p. 206-207)

Se o otimismo associado à religião da tecnologia dá sinais claros de seu potencial catastrófico, é preciso então a ele justapor uma crítica da tecnologia capaz de deixar entrever, para além do operacional e tão rigorosamente quanto possível, uma economia cultural de perdas e ganhos. No que se segue, essa crítica é dirigida 
primordialmente para a revolução nas práticas de leitura, a leitura do literário inclusive, com o aparecimento do hipertexto digital.

\section{Platão revisitado}

No conhecido mito platônico da invenção da escrita, o deus Theuth apresenta ao rei do Egito, Thamus, sua mais nova tecnologia e explica o seu funcionamento e as vantagens a serem contabilizadas para os egípcios que viessem a utilizá-la. Era já conhecida a fama de Theuth por outras invenções (technas): a matemática, o cálculo, a geometria, a astronomia. Theuth especializa-se em fabricar codificações do real para torná-lo passível de manipulação e controle. Em todos os casos, resulta da codificação um modelo do objeto representado que é, ao mesmo tempo, redutor e produtivo, já que traduz e transforma o concreto em uma forma de conhecimento abstrata e caracterizada pela força operacional. É o caso, por exemplo, da operacionalidade que, transformando as formas naturais em círculos, triângulos e retângulos, torna possível tanto a arte como o artefato. Não é diferente o modus operandi da nova tecnologia da escrita. Theuth explica: "Esta descoberta, ó rei, tornará os egípcios mais instruídos, pois representa o remédio (phármacon) tanto para a memória (mneme) quanto para o saber (sophia)" (PLATÃO, 1925, p. 274).

Os fonemas codificados em letras tornam-se produtivos porque constituem uma prótese da memória e do conhecimento vivos e interiorizados. Operacionalizados pela tecnologia, transformam-se em um sistema abstrato de sinais, um aparato capaz de compensar a limitação da memória humana. A fala de Theuth limita-se a descrever ao rei essa operacionalização do sistema de codificação. Interessa-lhe apenas um processo narrativo mínimo que, não por acaso, ocorre com frequência nos comerciais de nossos dias: existe um antes e um depois, o segundo melhor do que o primeiro graças à intervenção da tecnologia que, nesse contexto, só pode ser vista como algo que expande e amplia o potencial do estado de coisas anterior. E o contexto dessa narrativa mínima é, exclusivamente, aquele da operacionalização: um antes modificado por operações tecnológicas transforma-se em um depois melhorado.

A resposta do rei complica significativamente essa narrativa operacional mínima porque a ela acrescenta uma dimensão problematizadora: aquela de uma economia histórica e cultural que insere a operacionalização em um contexto mais amplo de perdas e ganhos do sujeito e da cultura afetados pela tecnologia:

Caro Theuth, o mais industrioso dos meus súditos, alguns se distinguem em inventar artes (ta technês); outros, em julgar o benefício. Está claro que tu, o pai das letras, por partidarismo, afirmas o contrário do efeito delas. Asseguro-te que elas causarão esquecimento (lethe) às psiques e desinteresse pela memória (mneme). A confiança dos iletrados repousará 
na escrita (graphé), em caracteres exteriores, estranhos, e não no interior, em reminiscências (anámnesis). Descobriste uma droga não para a memória, mas para a recordação (hipómnesis). Oferecerás a teus discípulos aparência (doxa) de saber, mas não a verdade (alétheia), pois os homens de letras se tornarão eruditos sem instrução; verão a si mesmos como intérpretes de muitas coisas, embora a maioria deles não saberá interpretar nada. Serão insuportáveis, sábios na aparência (doxósophos) e não sábios (sophós) de fato (PLATÃO, 1925, p. 274-275).

Na perspectiva do rei, que chama a atenção para o problema das posições partidárias dos outros, Theuth seria uma espécie de intelectual orgânico, já que só pode falar a partir do contexto produtivo a que está filiado, ou seja, o contexto tecnocrático. Thamus desloca essa perspectiva, que percebe apenas as vantagens da nova tecnologia, para uma economia cultural de perdas e ganhos. Há um preço a pagar para cada mudança comportamental causada pela tecnologia. A cada uso de uma faculdade humana corresponde um desuso, a cada nova forma de conhecimento, a possibilidade de perda de outro, que se torna obsoleto. Em resumo, o uso de um artefato protético, que substitui ou incrementa uma função humana, traz como efeito colateral uma certa atrofia do organismo.

Thamus propõe, portanto, uma crítica da perspectiva operacional e tecnocrática por meio de um deslocamento. O operacional, entendido em um novo contexto, significa outra coisa. Esse novo contexto é, precisamente, aquele que entende a tecnologia não apenas como um instrumental que desencadeia operações e implementa processos existentes, mas como uma força ambiental que afeta aqueles que a utilizam, alterando suas práticas e comportamentos e tornando-os diversos do que eram. O uso da escrita como prótese exterior, que complementa e expande o uso limitado da memória interior, resultaria, aos poucos, no uso cada vez menos intenso da memória interior, já que a informação que deveria ser antes retida na memória humana existe agora armazenada e disponível na escrita. A escrita, diz o rei, causará "esquecimento (lethe) às psiques e desinteresse pela memória (mneme)". E poderia, ainda, ser a causa de uma disseminação errônea de sentidos que, circulando no meio escrito e afastando-se de sua origem na voz do autor, escapariam ao controle que tal presença originária poderia supostamente exercer.

Ojulgamento de Thamus, que prioriza a voz e a presença em 1 Ver, em particular, o the letter" (DERRIDA, 1976). Derrida afirma que a história da metafísica "atribuiu sempre a origem da verdade em geral ao logos: a história da verdade, da verdade da verdade, trouxe sempre consigo (...) a desvalorização da escrita e a sua repressão no exterior da fala" (p.3). 
operacional e otimista de Theuth. Optar por uma em favor da outra, como faz o rei, é o resultado de um problema de miopia crítica. Mais apropriado e produtivo seria pensar a escrita e a fala não apenas como tecnologias alternativas, mas também como complementares. E trata-se de complementaridade que tem um potencial de crítica, já que o complemento constitui uma segunda dimensão (aquela de uma definição alternativa da tecnologia) a partir da qual é possível repensar a definição anterior e vice-versa. O fato de a voz e a comunicação presenciais terem o seu lugar e a sua hora não precisa necessariamente conduzir ao banimento da escrita para fora da história da verdade. Essa perspectiva crítica dupla, que leva em conta dialeticamente tanto a proposta do rei como a do inventor, pode, portanto, constituir o lugar crítico a partir do qual se torne possível entender o que se perde e o que se ganha quando do aparecimento de uma nova techné.

\section{O hipertexto operacional}

O livro de George P. Landow, The Convergence of Contemporary Critical Theory and Technology, foi o primeiro estudo sistemático dos possíveis relacionamentos entre o hipertexto eletrônico e a teoria literária. Encontra-se no texto uma passagem que, não por acaso, guarda certas semelhanças com a fala de Theuth: "Na medida em que qualquer leitor tem o poder de entrar no sistema e nele deixar a sua marca, nem a tirania do centro e nem a da maioria conseguem se impor. Pela sua própria natureza, o texto aberto confere poder ao leitor" (LANDOW, 1992, p. 173, trad. livre).

Landow não é aqui o inventor da nova tecnologia hipertextual, mas como Theuth, teoriza sobre ela em uma narrativa mínima de um antes e um depois que se referem, neste caso, ao leitor. Mas Landow vai além de Theuth porque explica o novo leitor, agora fortalecido, em termos de uma economia social de redistribuição de poder que deve necessariamente ocorrer com o aparecimento de uma nova tecnologia: "A tecnologia sempre confere poder a alguém, ou a um grupo social, e há um preço a pagar. A pergunta a ser feita, portanto, diz respeito ao grupo ou aos grupos sociais que se tornam mais poderosos" (LANDOW, 1992, p. 171, trad. livre).

Para que o leitor adquira mais poder, é necessário que alguém ou alguma coisa o perca. Os grandes perdedores são, aqui, o livro e o autor tradicionais que, de formas diversas, exerceram durante séculos o poder de controlar significativamente tanto o comportamento do leitor como a produção de significados. O autor tradicional constitui um centro de poder que organiza linearmente o seu texto em sentenças, parágrafos, capítulos, começo, meio e fim. Dificilmente poderia o leitor comum escapar de tais constrangimentos. $\mathrm{O}$ autor de hipertextos, por outro lado, produz o seu texto de acordo com o princípio da quebra da linearidade porque trabalha com um paradigma de construção textual que substi- 
tui sequências de sentido por saltos entre blocos de significado. Landow (2006) entende a passagem do texto ao hipertexto (e de autores e leitores do primeiro para autores e leitores do segundo) em termos de uma mudança radical de paradigma que constitui nada mais nada menos do que "uma revolução no pensamento humano":

Creio que uma mudança de paradigma começou a acontecer nos escritos de Jacques Derrida e Theodor Nelson, Roland Barthes e Andries Van Dam. Aqueles ligados à área de computação conhecem bem as idéias de Nelson e Van Dam; e aqueles que trabalham na área de teoria literária e cultural conhecem igualmente bem as idéias de Derrida e Barthes.

Todos eles, como muitos outros que escrevem sobre teoria literária, argumentam a favor do abandono de sistemas conceituais baseados em idéias de centro, margem, hierarquia e linearidade e da sua substituição por sistemas de multilinearidade, nódulos, links, e redes (p. 1, trad. livre).

O termo "paradigma" partilha com outros conceitos explicativos, como "modelo", "gênero" e "estrutura", o problema de tentar explicar classes de objetos através de procedimentos que, priorizando a identificação de semelhanças, relega a um segundo plano as diferenças. $\mathrm{O}$ sucesso desses procedimentos depende sempre da subordinação do fluxo temporal à dimensão do espaço geométrico e abstrato em que, por assim dizer, um presente eterno permite justapor lado a lado objetos dissimilares que podem, por um momento, ignorar suas diferenças. Subordinando o tempo ao espaço e a história à estrutura, o paradigma torna possível a percepção idealizada do mesmo no diverso e da unidade na multiplicidade. É óbvio que não se faz história sem estruturas e que a estrutura não escapa da historicidade. Mas é para o desequilíbrio entre essas duas dimensões que o conceito de paradigma chama a atenção, em contraste com o discurso explicativo ideal que tentaria, sempre de forma precária, equilibrar movimento temporal e imobilidade geométrica, atentando sempre para as limitações impostas tanto pelo excesso de fluxo como pela exorbitância da estrutura.

Uma leitura crítica da obra de Landow apontaria para a prioridade dada mais às semelhanças a serem obtidas pelo procedimento paradigmático do que para as diferenças históricas. Manifesta já no título do volume, que propõe uma convergência entre hipertexto e teoria literária, a ênfase nas semelhanças torna-se mais específica e problemática na justaposição de nomes citada acima: de um lado, Derrida e Barthes; de outro, Ted Nelson e Van Dam, todos considerados como adversários "de sistemas conceituais baseados em idéias de centro, margem, hierarquia e linearidade" e partidários de "sistemas de multilinearidade, nódulos, links e redes". Mas será que as constantes paradigmáticas 
de centralização e descentralização ocorrem da mesma forma ou em contextos idênticos? E será que a identificação das diferenças específicas implícitas nas constantes paradigmáticas não apontaria para o problema maior da justaposição de semelhanças genéricas, ou seja, o problema da generalização conceitual extremada que tornaria de pouca utilidade e, no limite, inútil, o sistema de semelhanças encontrado? Landow não enfrenta sistematicamente o problema, apesar de não se furtar a dar indicações ocasionais de sua existência. É o que acontece com a discussão das relações entre a proposta de descentramento da rede rizomática em Deleuze e as suas contrapartidas na teoria do hipertexto:

Qualquer leitor de hipertexto que tenha vivenciado as formas pelas quais as nossas atividades na rede textual produzem múltiplas versões e abordagens de uma unidade de significado perceberá que vale também para o hipertexto a idéia de Deleuze e Guattari de que "as multiplicidades são rizomáticas, e denunciam as pseudo-multiplicidades arborescentes pelo que elas são. Não existe uma unidade que possa servir de ponto de apoio ao objeto ou para estabelecer divisões no sujeito". Portanto, da mesma forma que o hipertexto entendido em sua forma mais genérica, "um rizoma não se submete a nenhum modelo estrutural ou gerativo. Revela-se alheio a qualquer idéia de eixo genético ou estrutura profunda" (LANDOW, 1992 , p. 60, trad. livre).

Estabelecida a semelhança, Landow (1992) apressa-se a chamar a atenção para um caveat:

Não devemos insistir muito nas semelhanças a ponto de presumir que as conceituações de rizoma, platô e pensamento nomádico [em Deleuze] equivalem exatamente às conceituações de hipertexto, uma vez que muitas das conceituações do rizoma e do pensamento rizomático não preenchem as exigências das tecnologias da informação que usam palavras, imagens, ou limitações de qualquer tipo. Quando, por exemplo, Deleuze e Guattari afirmam que um rizoma "não tem começo ou final, mas apenas um meio (milieu) a partir do qual cresce e transborda", apresentam um conceito que tem muito a ver com o tipo de hipertexto em rede quase-anárquico que encontramos na internet; mas quando acrescentam a seguir que o rizoma "compõe-se não de unidades, mas de dimensões, ou mais precisamente de direções em movimento", a contrapartida [no hipertexto] parece mais difícil de se concretizar" ( $p$. 61-62, trad. livre).

A falta de correspondência entre rizoma e hipertexto, que solicita um esforço explicativo rigoroso, não parece preocupar Landow. O teórico limita-se a dizer que "o rizoma é, essencialmente, um contra-paradigma, algo que não se realiza em nenhum momento ou cultura específicos, muito embora possa servir como um ideal para o hipertexto" (LANDOW,1992, p. 62, o itálico é meu). Há diferenças entre rizoma e hipertexto porque na prática a teoria é outra: o conceito teórico apresenta uma situação idealizada que 
encontra dificuldades de realização cada vez que se manifesta na materialidade limitada de, por exemplo, palavras ou imagens. $\mathrm{O}$ conceito idealizado de rizoma propõe a ausência de limites, que é incompatível com as limitações de um objeto tecnológico como um computador, por exemplo.

Em que consistiria, mais precisamente, esse ideal para além de qualquer prática? O próprio Landow (1992) sugere a possibilidade de um aprofundamento da questão quando afirma que o rizoma, como o "hipertexto entendido em sua forma mais genérica", rejeita "qualquer idéia de eixo genético ou estrutura profunda" (p. 60). O hipertexto genérico é aqui o equivalente do conceito ideal de rizoma. A distinção entre real e ideal, específico e genérico seria uma explicação satisfatória se não fosse possível encontrar estruturas rizomáticas na realidade material e histórica. Ora, essas estruturas existem: a linguagem é um exemplo. Se Deleuze estiver falando de realidades similares, que rejeitam origens e estruturas profundas, então a comparação entre o rizoma como ideal e o hipertexto como real cai por terra. Voltarei ao problema mais tarde, da forma como foi trabalhado por Martin Rosenberg, mas vale a pena registrar aqui que, se existem realidades que escapam à origem e à estrutura, então as diferenças entre rizoma e hipertexto podem ser explicadas também (e possivelmente melhor) na medida em que são "realidades" diversas, e não necessariamente definíveis em termos da distinção entre real e ideal. Mais precisamente, o rizoma é diferente do hipertexto porque, tratando de certas realidades da mesma natureza que a linguagem, revela-se diverso de uma prática de previsibilidade programável, que ocorre em um espaço geométrico de cálculo e do qual, como se verá a seguir, a temporalidade-duração é excluída. O hipertexto é diferente do rizoma não porque este último é uma idealização, mas porque acontece em uma dimensão ou em dimensões do real que resistem à programação geométrica, como o tempo, a linguagem e a história.

Pouco convincente em termos de rigor teórico, a escolha que faz Landow para explicar a convergência entre regimes pós-estruturalistas de descentralização e hipertexto em termos de real versus ideal é, contudo, uma indicação valiosa para o entendimento de sua obra como um todo. Trata-se de obra que tende a privilegiar mais uma prática de produção de redes hipertextualizadas de excelente qualidade do que uma postura crítica em relação ao hipertexto. Landow coordena atualmente a apresentação de três websites, dedicados respectivamente a estudos da era vitoriana, ao pós-colonialismo, e a questões relativas à teoria crítica, ciberespaço e hipertexto. São produções de grande valor e reconhecidas internacionalmente. Receberam prêmios que reconhecem sua excelência de instituições australianas, russas, inglesas e norte-americanas, entre outras. 
Mais próxima da perspectiva de Theuth do que da de Thamus, a imensa contribuição de Landow precisa, no momento atual, ser complementada por uma visão crítica que aponte para suas vantagens e desvantagens, seus usos e abusos e para o seu poder de, enquanto tecnologia hegemônica, relegar a um segundo plano práticas tecnológicas anteriores. É possível pensar essa revisão crítica em termos de duas perspectivas complementares, uma dedicada à revisão teórica do paradigma proposto por Landow, a segunda a uma crítica fundamentada na história. Estudos como o de Martin Rosenberg representam a primeira tendência e contribuições como a de Chartier, a segunda.

$\mathrm{Na}$ antologia de textos teóricos sobre hipertexto, organizada por George Landow e publicada em 1992, o ensaio escrito por Rosenberg parece ter sido feito sob medida para definir o seu autor como um advogado do diabo. Em meio a percepções mais ou menos otimistas em relação ao potencial que supostamente teria o hipertexto eletrônico de dar mais poder e liberdade ao usuário, agora beneficiado com intensa interatividade, o ensaio apresenta-se como crítica radical à visão progressista do hipertexto eletrônico. Para o crítico, essa perspectiva progressista pode ser melhor compreendida quando pensada no contexto das tradições de vanguarda obcecadas e deslumbradas pelo potencial revolucionário da "novidade" do novo. Seus representantes são teóricos que entendem os sistemas hipertextuais como

veículos para os propósitos artísticos e pedagógicos da vanguarda; acreditam que o hipertexto tem o potencial para "dar liberdade" aos seus usuários. [São] entusiastas que imaginam o hipertexto como tecnologia capaz de oferecer aos seus consumidores experiências educacionais e estéticas diversas e recompensadoras: textos de ficção e poesia no âmbito das artes e sistemas geradores de textos nas salas de aula (ROSENBERG, 1992, p. 270, trad. livre).

O problema é que o argumento usado para justificar o potencial revolucionário e libertador do hipertexto recorre, normalmente, ao uso de metáforas tomadas de empréstimo às ciências duras, como a física. O empréstimo, que busca dar legitimidade ao argumento, em virtude do prestígio do discurso científico, também resulta em distorção de sentido, o que é inevitável quando se tenta transferir significado de uma área de conhecimento para outra. Termos como geometria, não-linearidade, nódulos, contingência, indeterminação e entropia não significam a mesma coisa em áreas diversas. Nas ciências duras, princípios como nódulos, não-linearidade e indeterminação não são marcados com conotações de liberdade. No caso do hipertexto, contudo, esses mesmos princípios supostamente permitiriam ao leitor o exercício de uma liberdade maior do que seria possível no meio 
impresso. Saltando de significado para significado com um toque no mouse, o leitor

controla o cursor, [torna-se] um leitor-autor [wreader] que pode imobilizar (freeze) o texto, que sabe da existência da tecla home do Hypercard ou das configurações de mapeamento do programa Storyspace, (...) que pode, em um instante, obter uma perspectiva transcendente da trajetória da leitura-escrita (ROSENBERG, 1992, p. 274, trad. livre).

Rosenberg (1992) lembra que esse poder de controle atribuído ao leitor do hipertexto, caracterizado pela capacidade transcendente de "separar o observador do fenômeno observado", guarda semelhanças com "o controle sobre o ambiente natural tornado possível pelo cálculo de Leibnitz e Newton" (cf. LANDOW, 1992, p. 274). Amplamente utilizado nas ciências duras, como a física, mas também em disciplinas não tão duras, como a economia e a medicina, o cálculo é comumente entendido como a disciplina matemática que estuda a mudança temporal com o objetivo de obter o seu controle. Configura as formas matemáticas de domínio que, como diz Rosenberg, "torna possível aos astrônomos rastrear o movimento dos planetas ou cometas para frente e para trás no tempo e, para os profissionais de balística, avaliar a trajetória de projéteis para otimizar os seus 'efeitos'"' (ROSENBERG, 1992, p. 274, trad. livre). Em resumo (e aqui recai a ênfase maior da crítica de Rosenberg), o cálculo tem como objetivo o controle total ou parcial da contingência temporal e da imprevisibilidade, utilizando para tanto a matematização do tempo - ou seja, a subordinação do tempo ao espaço. Evidentemente, o controle do imprevisível não se aplica da mesma forma em situações diversas: sofre variações em áreas disciplinares como a física e a medicina, em práticas como um programa de computador ou a previsão do tempo e, ainda, em tentativas de calcular a estimativa de vida de um paciente que sofre de uma enfermidade fatal. No caso do hipertexto eletrônico, o controle das unidades de sentido e de suas variações é total: "todas as contingências disponíveis para o leitor-autor são domesticadas pelo domínio completo que ele tem sobre o processo de determinar direções" (ROSENBERG, 1992, p. 274, trad. livre).

A crítica de Rosenberg propõe, portanto, uma indagação crucial a respeito do tipo de poder e liberdade que a interatividade hipertextual supostamente atribui ao seu leitor. A liberdade de um leitor-autor de hipertextos, que controla as múltiplas trajetórias de sentido e decide quais unidades de significado podem ser conectadas a quais outras, pode, no final de contas, ser uma liberdade radicalmente restrita, em virtude do que Rosenberg chama de "as dimensões explicitamente geométricas do hipertexto" (ROSENBERG, p. 274). Se lembrarmos que a geometria é uma disciplina marcadamente voltada para as formas espaciais, a natureza geométrica do hipertexto já havia sido antecipada pelo 
trabalho anterior de Bolter em Writing Spaces (1991). No livro, Bolter caracteriza o hipertexto como uma forma de "escrita topográfica", entendendo-se "topografia" não simplesmente em termos da "descrição verbal de um lugar", mas principalmente no seu sentido mais recente e específico de "reprodução visual e matemática de um local". É pela sua natureza topográfica que a escrita eletrônica configura-se como uma "atividade de escrever com lugares e com tópicos espacialmente distribuídos" (BOLTER, 1991, p. 25, trad. livre). Escrever com lugares ou tópicos é uma outra forma de definir aquele controle newtoniano, exercido pelos astrônomos, a que se refere Rosenberg. O que faz tanto o astrônomo quanto o produtor de hipertextos é configurar, na dimensão plana de um mapa, lugares, tópicos, ou unidades de sentido interligadas com o objetivo de controlar o real. Feito o mapeamento, é possível, no caso da textualidade astronômica, "rastrear o movimento dos planetas ou cometas para frente e para trás no tempo"; no caso do hipertexto, rastrear as unidades de sentido também para frente e para trás no tempo. Nos dois casos, o tempo real e irreversível, submetido à geometria, adquire aquela mesma reversibilidade característica de um relógio que, também para fins de controle, reduz o tempo a um espaço geométrico.

Evidentemente, essa redução do tempo ao espaço, típica da escrita topográfica, não se limita aos textos gerados por computador. Acontece em outras práticas culturais e a outras formas de escrever. Mas, como explica Bolter (1991), é com o computador que essa prática de escrever com lugares ou tópicos atinge o seu estágio mais perfeito e completo:

A escrita topográfica enquanto forma de expressão não se limita ao computador. É possível escrever topograficamente no meio impresso ou mesmo em manuscritos. Cada vez que dividimos um texto em tópicos unitários a serem organizados em uma estrutura de conexões e cada vez que pensamos tal estrutura como ao mesmo tempo verbal e espacial, estamos escrevendo topograficamente (...). Muito embora o computador não seja indispensável para a escrita topográfica, é somente nele que essa forma de escrita se torna a forma natural e, portanto, também convencional, de escrever ( p. 25).

Aprisionado em uma topografia que, pela sua natureza geométrica, subordina o tempo a um espaço de programação e reversibilidade temporal, o hipertexto permite ao seu leitor sonhar com uma grande possibilidade de escolha de caminhos a serem percorridos. É até possível que o leitor tenha a impressão de uma liberdade quase infinita, em função da imensa quantidade de possibilidades interconectadas que pode ser programada em um banco de dados. Mas essa impressão de multiplicidade infinita de escolhas é ilusória, já que não difere daquela que tem, por exemplo, o leitor que opera nos limites de um mapa para traçar roteiros alternativos. No dizer certeiro de Rosenberg, trata-se 
daquela forma de libertação que não se deu conta de ter caído na armadilha "da geometria logocêntrica do tempo-espaço regrado" (ROSENBERG, 1992, p. 274; o itálico é meu). A referência ao logocentrismo de Jacques Derrida é importante porque lembra, mais uma vez, a natureza problemática das aproximações apressadas entre teóricos do hipertexto e representantes do pós-estruturalismo. A contribuição crítica maior de Rosenberg está, justamente, na demonstração de que a conceituação de liberdade é radicalmente diversa nos dois casos. Qual seria, então, a diferença?

Para Rosenberg, a diferença pode ser compreendida em termos de duas tradições de pensamento a respeito da liberdade, uma voltada para o significado essencialmente temporal do conceito, a outra para o seu sentido em termos de topografias programáveis. A primeira, que Rosenberg caracteriza como típica das vanguardas culturais após a primeira Revolução Industrial (no final do século XVIII e inícios do século XIX), tinha como uma de suas diretrizes a resistência ao controle exercido pelos "relógios mecânicos e pelo cálculo", evidenciada em uma "celebração obsessiva da contingência" (ROSENBERG, 1992, p. 276). $\mathrm{Na}$ forma como foi pensada por Bergson, essa contingência é aquela vivenciada pela consciência humana na duração temporal da realidade, marcada pela irreversibilidade do tempo, pelo imprevisível e pelo não programável. A vivência dessa consciência humana livre ocorre precisamente na medida em que, aceitando e incorporando o imprevisível, exercita-se em uma dimensão de instabilidade e fluxo, e não de estabilidade programada. Trata-se, portanto, de uma consciência humana mais desvinculada de constrangimentos precisamente porque escapa de toda e qualquer "construção ideológica geométrica". São estas que, como no caso do hipertexto, constituem redes de controle que enredam tanto os programadores como os leitores. Ser verdadeiramente livre, portanto, significa escapar das máquinas calculadoras que tem por função "escamotear a natureza da consciência humana com o objetivo de planejar horários industriais, trajetórias de balas de canhão e a circunavegação do globo" (ROSENBERG, 1992, p. 287 , trad. livre). E é também essa dimensão da liberdade que, de acordo com Rosenberg, pode ser encontrada em pensadores do pós-estruturalismo como Deleuze e Guattari, que foram influenciados pela obra de Bergson. O conceito de micro e macro-política da criatividade em Deleuze, por exemplo, fundamenta-se na "premissa de que somente táticas de subversão que se mostram indiferentes à geometria podem produzir um estado de liberação, uma morte localizada" (ROSENBERG, 1992, p. 291, trad. livre).

\section{Para além do hipertexto operacional: história da leitura e crítica do hipertexto}

A crítica de Rosenberg ajuda, portanto, a compreender as limitações do uso do hipertexto que tendem a passar desperce-

Niterói, n. 35, p. 63-82, 2. sem. 2013 
bidas quando a perspectiva operacional torna-se dominante e justifica o seu uso em termos de força progressista e libertadora. Há, contudo, um segundo viés crítico, talvez mais significativo, que provém da história da leitura e que ajuda a melhor entender a presença hegemônica do hipertexto no momento atual em termos de perdas e ganhos culturais. O esforço recente mais significativo, nesse sentido, é a coletânea de ensaios preparada por Guglielmo Cavallo e Roger Chartier e publicada sob o título de $A$ History of Reading in the West. ${ }^{2} \mathrm{O}$ volume cobre momentos decisivos da história da leitura desde a civilização grega até o momento contemporâneo, em que a forma hegemônica de ler depende cada vez mais da presença dominante do hipertexto. Trata-se de um estudo macro-historiográfico que completa o estudo de Rosenberg não apenas porque este último enfatiza a comparação entre paradigmas (a tradição vanguardista e os teóricos do hipertexto), mas também porque representa (como não poderia deixar de acontecer, já que o paradigma imobiliza a diacronia, mas dela não escapa) uma contextualização micro-historiográfica voltada para um momento histórico restrito. A crítica de Rosenberg, que limita o contraste paradigmático aos discursos dos últimos sessenta anos, tem o mérito de mostrar que, nesse período, a mudança temporal exige cuidado do pesquisador, pois as manifestações discursivas, mesmo quando ocorrem simultaneamente ou em um intervalo mínimo de anos, podem ter natureza diversa, uma vez que oriundas de tradições alternativas de pensamento (vanguarda, teóricos do hipertexto). Rosenberg está próximo de uma perspectiva analítica que tende para a percepção da história em termos de eventos singulares ou quase singulares, o que significa que não se repetem.

Não é essa micro-história sem repetições que encontramos na coletânea organizada por Chartier e Cavallo. Trata-se, antes, de uma macro-história em que tudo se repete, mas com diferenças. A história não é aqui uma narrativa mítica em que o mesmo prevalece porque nada de novo pode acontecer na estrutura prevista in illo tempore, ou seja, desde sempre e para sempre, mas uma narrativa em que as tecnologias de produção textual e as leituras que a elas correspondem podem ocasionalmente desaparecer (o pergaminho de rolo caiu em desuso). Elas podem, também e mais comumente, transformar-se ou mesmo reaparecer em novas formas (na leitura de textos em um computador, o usuário normalmente lê textos em um movimento descendente semelhante ao movimento de leitura descendente de um texto em pergaminho de rolo). É esse

2 Publicado originalmente em francês (Histoire de La lecture dans le monde occidental: Rome-Bari, Giuseppe Laterza \& FigliSpa, 1995), foi traduzido para o inglês em 1999. Uso nesse ensaio a tradução em inglês. processo histórico de desaparecimento, transformação e adaptação de novas tecnologias textuais que torna possível um segundo entendimento crítico do hipertexto, que vai além de sua dimensão primariamente operacional. Entendido historicamente, o hipertexto eletrônico revela-se como, ao mesmo tempo, continuidade e ruptura em relação ao passado. E tanto as continuidades como 
as rupturas ajudam a entender a mudança histórica provocada pelas novas tecnologias em termos de perdas ou enfraquecimento de certas práticas culturais de produção e leitura de textos e, simultaneamente, das novas formas que as substituem ou modificam. Não custa apontar aqui, de passagem, a importância do entendimento dessa economia de perdas e ganhos culturais para uma crítica das novas formas de textualidade. A percepção das perdas e ganhos culturais resultantes da hegemonia cultural do hipertexto eletrônico é necessária e urgente, particularmente quando se considera a velocidade inédita da expansão e uso das novas tecnologias.

É preciso salientar, ainda, que boa parte da força explicativa da historiografia desenvolvida no volume advém do esforço para entender a produção e leitura de textos na materialidade de suas práticas cotidianas. "A leitura", dizem os organizadores do livro, "não é uma operação intelectual meramente abstrata; envolve o corpo, está circunscrita em um espaço, e implica um relacionamento entre uns e outros" (CAVALLO E CHARTIER, 1999, p. 4, trad. livre). E é essa ênfase na materialidade das práticas de ler e escrever que permite melhor compreender como certas "formas de leitura do mundo contemporâneo desapareceram ou tornaram-se marginais" (CAVALLO E CHARTIER, 1999, p. 4, trad. livre). Esses desaparecimentos e marginalizações tornam-se mais visíveis nas duas grandes revoluções nas práticas de produção e leitura de textos: a primeira, na passagem do medievo para a modernidade (séculos XII a XV, aproximadamente), quando a prática de leitura silenciosa torna-se dominante e a invenção da imprensa torna possível um vasto aumento na circulação de textos; e a segunda, na passagem do século XVIII ao século XIX, quando uma nova expansão da produção impressa coincide com o aparecimento de uma nova prática de leitura, denominada por alguns historiadores de "leitura extensiva", em contraste com a predominância de uma suposta "leitura intensiva", anteriormente existente. A essas revoluções do passado segue-se a terceira revolução, que acontece no momento contemporâneo, com a hegemonia do hipertexto eletrônico, que provoca novas mudanças nas práticas de leitura. Dedicada ao estudo histórico da produção e consumo de textos, a antologia de Cavallo e Chartier, embora não aborde sistematicamente as semelhanças e contrastes entre essas três revoluções, torna possível entrevê-las e aponta para a necessidade de estudos comparativos mais específicos. Estes, por sua vez, ampliariam os estudos de semelhanças e contrastes e abririam caminho para uma compreensão crítica do hipertexto eletrônico para além de sua prática meramente operacional.

Na passagem do medievo tardio para a modernidade, dá-se a conjunção do desenvolvimento paulatino de novos hábitos de leitura e a invenção da imprensa. É a interação dos dois fatores, e não apenas o aparato tecnológico de Gutenberg, que melhor

Niterói, n. 35, p. 63-82, 2. sem. 2013 
descreve a revolução. A inegável importância da nova tecnologia manifesta-se na grande expansão da circulação de textos, no baixo custo obtido na produção do livro e na reprodução relativamente rápida de cópias idênticas. Cada livro podia assim chegar às mãos de um número cada vez maior de leitores e "cada leitor individual podia ter acesso a um número cada vez maior de livros" (CAVALLO, CHARTIER, 1999, p. 22, trad.livre). Mas a invenção da imprensa deve ser entendida no contexto da passagem gradual da cultura medieval dos escribas para a cultura impressa. $\mathrm{Na}$ primeira, presente a partir dos inícios da Idade Média, "ocorre a passagem da leitura em voz alta para a leitura em murmúrio, a exemplo da ruminatio dos monges, que liam murmurando as palavras" (CAVALLO, CHARTIER, 1999, 18, trad. livre). E a prática da leitura era, sobretudo, voltada para "a obtenção do conhecimento de Deus, e para aumentar as possibilidades da salvação" (CAVALLO, CHARTIER, 1999, p. 17). O ritmo era necessariamente lento: "os textos deveriam ser compreendidos, meditados e até mesmo memorizados" (CAVALLO, CHARTIER, 1999, p. 17, trad. livre); e eram poucos os livros disponíveis para leitura. Na segunda forma de leitura, a partir dos finais do século XI, altera-se o comportamento do leitor:

A leitura já não era orientada para uma compreensão simples do significado literal (littera) do texto; esse tipo de compreensão era apenas um começo, a partir do qual o leitor deveria procurar o sentido do texto (sensus), para chegar depois à proposição (sententia), ou doutrina, em toda a sua profundidade. Os livros e a leitura submetem-se ao controle da ratio: a Razão, que discute os usos dos livros com o Prazer, no De librorum copia de Petrarca, critica a obsessão pelo acúmulo inócuo de volumes e define em linhas gerais uma teoria (mas também uma história) da prática de leitura que teria por objetivo fixar o livro "na mente", e não "na estante" (CAVALLO, CHARTIER, 1999, p. 18, trad. livre).

O surgimento de um novo tipo de leitura, que percebe o texto como um instrumento para o aprimoramento da mente, começa a tornar obsoleto o conceito de texto enquanto "depositório de coisas para ruminar (ruminare), ou simplesmente enquanto objeto a ser possuído" (CAVALLO E CHARTIER, 1999, p. 18, trad. livre). E correspondem a esse novo tipo de leitura, dedicado à obtenção do conhecimento e organizado pela ratio, novos tipos de formatação de textos, mais adequados para uma procura de conhecimento que pode ser obtido em um livro organizado sequencialmente, mas que pode também requerer um tipo de consulta não linear, fundamentado mais na justaposição de fragmentos do que na ordem cronológica de começo, meio e fim. Cavallo e Chartier descrevem sucintamente as novas técnicas de formatação, direcionadas para "a rápida identificação da passagem procurada pelo leitor: rubricas, separação e sinalização de parágrafos, títulos de capítulos, 
a separação orgânica e correlacionada de texto e comentário, resumos, correlações de termos, índices, e tabelas analíticas em ordem alfabética" (CAVALLO, CHARTIER, 1999, p.19, trad. livre). As bibliotecas, por sua vez, adaptam-se também às novas exigências da procura de informação e conhecimento: o catálogo deixa de ser um inventário para transformar-se em ajuda de consulta, indicando o "local preciso dos volumes de uma biblioteca ou até mesmo de uma área geográfica" (CAVALLO, CHARTIER, 1999, p. 19 , trad. livre). E, ao contrário das bibliotecas anteriores em que o murmúrio da leitura era uma presença constante, "a característica da nova biblioteca era o silêncio: os livros eram consultados em um silêncio perturbado apenas pelo barulho das correntes que os atavam às mesas de leitura" (CAVALLO, CHARTIER, 1999, p. 19, trad. livre).

No período imediatamente anterior à modernidade (séculos XII a XV), o livro, a biblioteca e a leitura começam a tomar a forma que permaneceria vigente pelos séculos seguintes: o livro passa a ser um volume organizado para ser lido em silêncio por um indivíduo isolado ou em uma biblioteca equipada com catálogo com o objetivo de obter ou ampliar conhecimentos através de uma leitura linear ou fragmentada. É esta última forma de leitura e consulta que, de forma mais intensa, estimula o aparecimento das formatações alternativas de textos mencionadas anteriormente. Um aperfeiçoamento posterior desse aparato para consulta apareceria no século XVI com a invenção da roda de leitura. Projetada pelo engenheiro militar italiano Agostino Ramelli em 1588, consistia em uma roda giratória vertical, capaz de acomodar vários livros, a serem consultados por um leitor que podia voltar sua atenção de um para o outro sem sair do seu lugar.

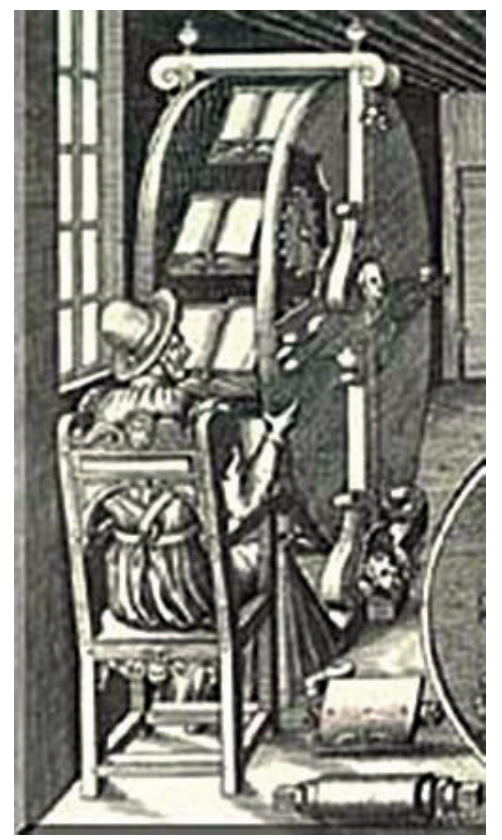

Roda da leitura, projetada por Agostino Ramelli (1558) 
Mas o aparato tecnológico que facilita a leitura fragmentada deve também ser entendido no contexto do momento histórico posterior à invenção da imprensa, que testemunhou um aumento significativo na quantidade de livros disponíveis para consulta. Tornava-se possível nesse momento ler uma variedade maior de textos, imediatamente acessíveis ao leitor. A prática anterior de leitura completa e intensiva de poucos livros, a serem lidos um de cada vez, perde vigor cultural, tornando-se uma alternativa entre outras. O surgimento ou a intensificação de uma nova maneira de ler, silenciosa e fragmentada em contraste com as práticas anteriores de leitura, ainda parcialmente vocalizadas e predominantemente lineares, não deixa de guardar semelhanças com momentos históricos futuros, que registraram desdobramentos da nova forma de organizar a informação e o conhecimento para a leitura. A roda da leitura poderia ser pensada como uma manifestação concreta do "princípio enciclopédico", ou seja, o princípio que permite imaginar a concentração de vários livros em um único volume. $\mathrm{Ou}$, ainda, se considerarmos o livro como um fragmento de um todo maior, a roda da leitura poderia ser vista como um exemplo do "princípio antológico". O que é importante ressaltar, no contexto do presente trabalho, é que são dois princípios que se manifestam com mais intensidade em momentos históricos marcados por uma grande expansão das tecnologias de acúmulo e disseminação da informação, como é o caso do período posterior à invenção da imprensa. São momentos históricos em que a necessidade de controlar o volume crescente de informação motiva o aparecimento de novas tecnologias e de novas práticas de leitura ou consulta. O século XVIII, quando a expansão do volume de livros, tornada possível pela invenção da imprensa atinge a sua plenitude, é o século áureo do princípio enciclopédico. A primeira edição da Enciclopaedia Britannica, em três volumes, aparece entre 1768 e 1771, e a Encyclopédie é concluída em 1772, sob a organização de Diderot e D'Alanbert e com a colaboração de luminares da épo-

3 Embora seja possível pensar a existência de um impulso enciclopédico pelo menos desde Aristóteles, cuja obra cobre uma vasta extensão das áreas do conhecimento histórico da época, a enciclopédia moderna, sistematicamente organizada em ordem alfabética e claramente programada com o objetivo de abarcar, tanto quanto possível, a totalidade do conhecimento relevante, é melhor compreendida quando situada historicamente como um gênero típico do século XVIII e impulsionado pela invenção da imprensa. ca, como Rousseau e Voltaire. ${ }^{3}$ Como a enciclopédia, a antologia pode ser vista como uma tecnologia análoga à roda da leitura, já que permite ao leitor consultar vários fragmentos sem sair do seu lugar. O termo "antologia" é derivado do grego e significa uma coletânea de flores ou poemas. Até o início do século XVII, o hábito de coletar raridades e objetos de arte, inclusive livros, era privilégio da monarquia e da nobreza. Na Europa do século XVIII, contudo, transforma-se em uma atividade mais popular, acessível à classe média e, em alguns casos, até mesmo à classe operária. As coletâneas eram constituídas não apenas por raridades como pinturas, relógios ou livros raros, mas também por objetos de valor duvidoso, como pedras de formato inusitado ou perucas. No século XVIII, a antologia especificamente literária ativa mais intensamente o princípio da enciclopédia em virtude da possibilidade da produção em massa do texto impresso e de 
custo relativamente baixo. Era possível, mais uma vez, sonhar com a possibilidade de resumir uma biblioteca de vários autores ou de vários gêneros de discurso em um só volume para consumo pessoal. Como explica concisamente Bárbara M. Benedict, "a antologia é a manifestação da grande mudança histórica da cultura oral para a cultura impressa e de um produto de elite para um produto de consumo de massa, e afetou a natureza da literatura no início do período moderno" (BENEDICT, 2003, p. 235, trad. livre).

Mais recentemente, o princípio enciclopédico, ativo tanto na roda do livro como nas enciclopédias e antologias, aparece novamente no memex" (memory expander) de Vannevar Bush, frequentemente entendido como invenção análoga, em muitos aspectos, ao hipertexto eletrônico. Repete-se aqui, com uma diferença, o momento histórico da roda do livro, marcado pela expansão da produção textual e da prática de leitura fragmentada. Em "As we may think", Bush identifica no pós-guerra o novo desafio que se apresenta ao cientista na forma de um excesso de conhecimento a ser controlado. O pesquisador, diz Bush, "perde-se diante das descobertas e conclusões de milhares de colegas - conclusões que, à medida que aparecem, ele não tem tempo de lembrar, e muito menos de digerir" (BUSH, 1945, p. 2, trad. livre). A nova máquina por ele imaginada para controlar o volume crescente de informação seria o memex um "conjunto de telas inclinadas e translúcidas sobre as quais seria possível projetar conteúdos escolhidos para leitura" (BUSH, 1945, p. 13, trad. livre). A projeção de conteúdos seria obtida com a ajuda de um teclado no qual o pesquisador digitaria códigos pré-programados:

Se o operador quiser consultar um livro específico, basta digitar o código equivalente no teclado e a página contendo o título aparece diante dele, projetada em uma tela (...). Movendo uma das alavancas para a direita, pode percorrer as páginas do livro que tem diante de si (...). Movendo para a esquerda, terá o mesmo tipo de controle [das páginas anteriores]" (BUSH, 1945, p. 13, trad. livre).

Descontado o fato de Bush estar ainda pensando no contexto da tecnologia de cunho analógico existente em meados da década de quarenta, ou seja, a tecnologia do microfilme, a descrição de um desktop para procura rápida e eficiente, em um vasto banco de dados, descreve com precisão o que viria a ser realidade nos futuros microcomputadores, equipados com a tecnologia digital necessária para a operacionalização do hipertexto eletrônico. À tecnologia da roda do livro e do memex corresponderia, a partir da década de setenta, a tecnologia hipertextual, tornada possível pela invenção do chip eletrônico, capaz de controlar a vasta quantidade de informação disponível em bancos de dados espalhados pelo planeta.

A semelhança entre tecnologias como a roda do livro, o memex e o hipertexto eletrônico, esquematicamente estabelecida 
aqui a partir da proposta historiográfica de Cavallo e Chartier, permite o entendimento mais claro da segunda postura crítica, complementar em relação ao trabalho de Rosenberg e capaz de clarificar o sentido do hipertexto para além de seu viés operacional. Entendido em um contexto histórico, o hipertexto repete, com diferenças, momentos anteriores em que o impacto de novas tecnologias altera hábitos de leitura, torna obsoletas certas práticas culturais e promove a hegemonia de outras. Torna-se então possível pensar o hipertexto eletrônico não apenas ou primariamente em termos de celebração eufórica das novas possibilidades abertas de democratização do conhecimento, liberdade de escolha e da expansão de poder e controle do autor e do leitor. Percebe-se também que, como no passado, a nova tecnologia insere-se em um contexto complexo de produção e consumo que afeta profundamente as práticas culturais existentes, excluindo algumas, promovendo outras e estabelecendo novas formas de poder discursivo. Acontecendo no momento de uma expansão do volume de informação disponível e clamando por novas formas de controle, a roda do livro e o memex promovem a implementação de uma prática fragmentada de leitura. Essa mesma prática parece ocorrer agora com a internet, quando a leitura tende a se fazer em termos de saltos quase instantâneos de uma unidade de sentido para outra e da procura de uma variedade constante em uma dimensão de horizontalidade que não pode ser senão inimiga, por exemplo, da prática de leitura vertical e reflexiva típica da cultura do livro impresso em mais especificamente, de certos gêneros literários. Se considerarmos, por exemplo, que a poesia solicita a seus leitores uma postura meditativa semelhante àquela existente no medievo, quais seriam as suas possibilidades de sobrevivência em um momento histórico em que as novas tecnologias motivam a prática de leitura marcada por movimentos rápidos entre fragmentos de significado? As consequências educacionais, políticas e econômicas de tal mudança merecem aquela atenção crítica marcada não apenas pela celebração acrítica e pela ideologia do "quanto mais melhor", mas também pelo exame cuidadoso do desaparecimento ou enfraquecimento de práticas culturais das quais não se pode simplesmente dizer que pertencem ao passado, são obsoletas e devem desaparecer, como no caso da leitura reflexiva e vertical. Como na narrativa do mito platônico, o equilíbrio entre as posturas de Theuth e Thamus é mais necessário do que nunca.

Abstract
The utopian perception of electronic hypertext as
a technology capable of revolutionizing reading
habits and empowering the reader can only pros-
per if the nature of technology is taken for granted 
as a merely instrumental structure and not as a structuring force capable of producing a new cultural economy of values. This paper advances $a$ critique of the instrumental and operational view to be developed as a continuation of the pioneering work proposed by theoreticians such as Martin Rosenberg and Roger Chartier.

Keywords: hypertext; digital utopia; critique of technology.

\section{REFERÊNCIAS}

BEBEDICT, Barbara C. The Paradox of the Anthology: Collecting and Différence in Eighteenth-Century Britain. New Literary History, n. 34, p. 231-256, 2003.

BOLTER, Jay David. Writing Space: The computer, hypertext and the history of writing. Hillsdale, New Jersey: Lawrence Erbaum Associates, 1991.

BUSH, Vannevar. As We May Think. Disponível em:www.theatlantic.com/unbound/ flashbacks/Computer/bush.htm. 1945. Acessado em 9 de junho de 2014.

CAVALLO, Guglielmo; CHARTIER, Roger. History of Reading in the West. London: Polity Press, 1999.

DERRIDA, Jacques. Grammatology. Trad. Gayatri Chakravorty Spivak. Baltimore: Johns Hopkins University Press, 1976.

DERRIDA, Jacques. Ulysses Gramophone: Hear say yes in Joyce. Trad. Derek Attridge. In: Acts of Literature, ed. Derek Attridge. London: Routledge, 1992. p. 253-309.

LANDOW, George P., ed. The Convergence of Contemporary Critical Theory and Technology. Baltimore, London: The Johns Hopkins University Press, 1992.

LANDOW, George P. Hypertext 3.0. Baltimore: The Johns Hopkins University Press, 2006.

NOBLE, David. The Religion of Technology: The Divinity of man and the spirit of invention. London: Penguin, 1999.

PLATÃO. Phaedrus. In: Plato, 12 vols., Vol. 9. Trad. Harold N. Fowler. Cambridge, MA: Harvard University Press; London: William Heinemann Ltd. 1925.

ROSENBERG, Martin L. Liberation and Complicity in Art and Pedagogy. In: Hyper/Text/Theory, ed. George P. Landow. Baltimore: The Johns Hopkins University Press, 1994, p 260-283. 